\title{
Risk Assessment in Pakistani Health Workers During COVID-19 Pandemic
}

\author{
Hafiza Nabeela Amaan ${ }^{1,2}$, Muhammad Babar Khawar ${ }^{3,4,5, *}$, Muddasir Hassan Abbasi ${ }^{6}$, Nadeem Sheikh ${ }^{5, *}$ \\ ${ }^{1}$ Institute of Clinical Nutrition \& Dietetics, Gulab Devi Educational Complex, Lahore-Pakistan. \\ ${ }^{2}$ Gulab Devi Chest Hospital, Lahore-Pakistan. \\ ${ }^{3}$ Institute of Zoology, Chinese Academy of Sciences, Beijing 100101, China. \\ ${ }^{4}$ University of Chinese Academy of Sciences, Beijing 100049, China. \\ ${ }^{5}$ Department of Zoology, University of the Punjab, Q-A-Campus, Lahore, 54590, Pakistan. \\ ${ }^{6}$ Department of Zoology, University of Okara, Okara, Pakistan.
}

\section{Dear Editor,}

The emergence of an outbreak and spread of a mysterious disease, at the end of 2019 , caused by a novel coronavirus (2019-nCoV or SARS-CoV-2) has threatened the world. It was originated in Wuhan (China) and quickly spread across the borders and about 216 countries/ territories have been affected by this disease called coronavirus disease 2019 (COVID-19) [1]. This new public health crisis is suspected to be originated in bats and then transmitted to humans via the yet unidentified intermediate host.The COVID-19 is transmissible via inhaling the infected droplets (either through direct contact or indirect contact with infected surfaces/ objects) and its incubation period has been observed between 5-6 days on average and can be up to 14 days. Dry cough, sore throat, high body temperature, malaise, and fatigue have been described as the major symptoms of COVID-19 [2]. At present, there are about 14, 529, 009 reported cases, and 478,219 confirmed deaths globally due to the COVID-19 pandemic [3].

The first confirmed case of COVID-19 in Pakistan was reported on February 26, 2020, in Sindh province [4]. In the beginning, the situation seemed under control and new cases raised quite slow. However, gradually the situation got worse and a sharp increase in the number of COVID-19 patients has been seen recently as a result of an increase in the number of tests conducted to screen the extent of COVID-19. At present, there are 282, 645 cases, and 6, 052 reported deaths. The Sindh and Punjab provinces are the worst struck with 122, 759, 94, 040 cases respectively to date [5].
Upon the emergence of any public health crisis or appearance of a natural disaster, the first force to respond to it is the health workers. However, their work and services are not appreciated to the deserved level and are mostly remain underrated [5]. At the time of emergence and then during the spread of this mighty pandemic (COVID-19) the medics and health professionals were the people who were the first to respond to help the sufferers of this disease without considering the risk of their own lives [6].

Similarly, in Pakistan, a force of doctors, physicians, paramedics, and other health professionals are busy at the front line in combating this global pandemic with their full energies and honesty. They are not only sacrificing their comfort rather risking their lives willingly to serve the nation at this difficult time. Pakistan is a developing country and currently facing a large number of challenges both internally and externally and do not have plenty of resources to fight such kind of natural disasters for a longer period. Therefore, there are several reports where these health workers are serving even with inadequate personal protecting equipment (PPEs) due to a lack of resources.

Pakistan confirmed the demise of the first doctor from Gilgit-Baltistan, in March 2020, who caught the SarsCoV-2 while dealing with COVID-19 patients. The death of a very young (26 years) old doctor drowned the whole nation in extreme sadness. A total of 2, 201 health workers were infected and 24 among them

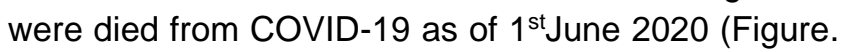
1). Among the infected health workers, 1, 240 were doctors, 333 were nurses, and 628 were paramedics. Among the deceased health workers, 15 were 
doctors, 2 were nurses, 1 was a medical student and 6 were paramedics. These affected health workers were $2.88 \%$ of the total COVID-19 patients in Pakistan and the health workers who died from COVID-19 were $1.48 \%$ among all the deaths (Figure. 1). Regarding the provincial situation, Punjab province has reported a total of 341 health workers affected and 7 of them have died. Similarly, Sindh province has reported a total of 538 health workers affected and 8 of them have died. In KPK, 552 health workers were found infected and 4 of them have died. While in Balochistan, 237 were found COVID-19 positive and 2 have died. Gilgit-Baltistan reported 42 total infected health workers and 2 reported deaths. Islamabad has 185 health workers infected with the virus and 1 reported death as of $29^{\text {th }}$ May 2020 (www.nih.org.pk/). A total of 2, 550 health workers fighting on the frontline have contracted the disease and unfortunately, 25 of them have lost their lives (Figure. 1) as of $4^{\text {th }}$ June 2020 [7]. The health workers are $2.99 \%$ of the total COVID-19 patients in Pakistan and the health workers who died from COVID-19 were $1.41 \%$ of all the deaths.
A

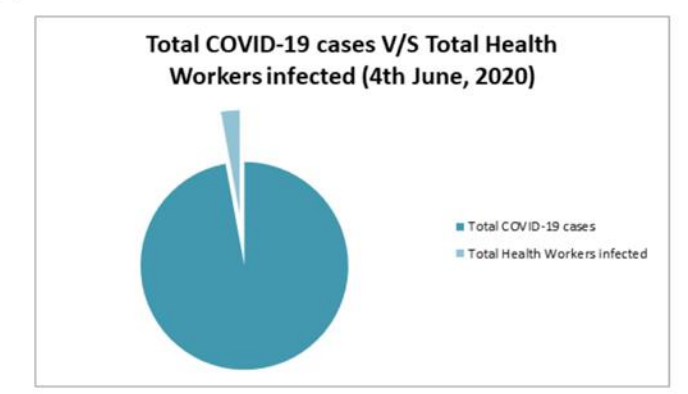

C

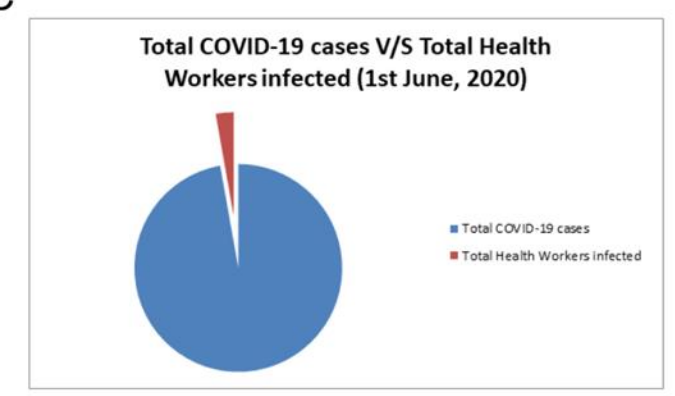

E

Total deaths from COVID-19 V/S Total Health Workers died (1st June, 2020)

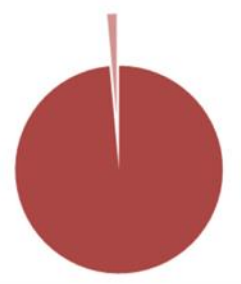

B

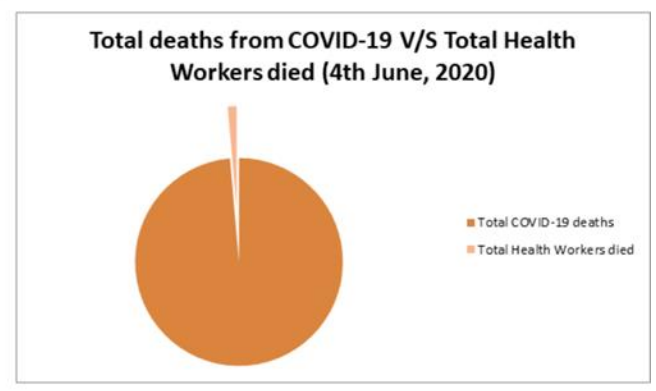

D

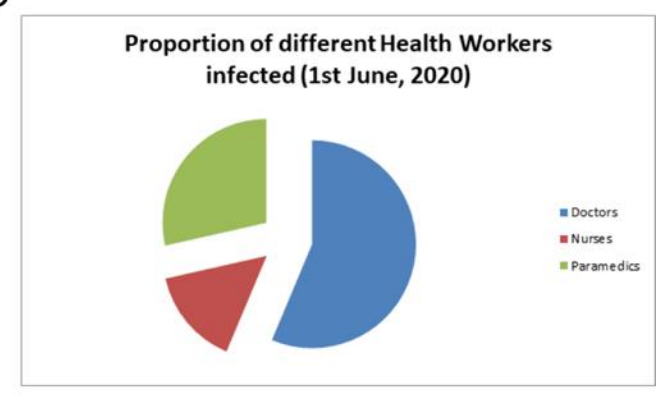

$\mathrm{F}$

Proportion of different Health Workers died (1st June, 2020)

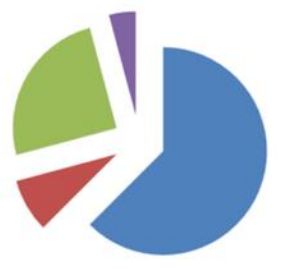

Doctors

- Nurses

- Paramedics

Figure 1. A comparison of COVID-19 patients and health workers infected from coronavirus. (A) Graphical representation of the proportion of total COVID-19 patients and health workers as of $4^{\text {th }}$ June 2020. (B) Graphical representation of the proportion of total deaths due to COVID-19 and health workers deceased as of $4^{\text {th }}$ June 2020. (C) Graphical representation of the proportion of total COVID-19 patients and health workers as of $1^{\text {st }}$ June 2020. (D) Graphical representation of the proportion of different types of health workers infected from COVID-19 as of $1^{\text {st }}$ June 2020. (E) Graphical representation of the proportion of total deaths due to COVID-19 and health workers deceased as of $1^{\text {st }}$ June 2020. (F) Graphical representation of the proportion of different types of health workers died from COVID-19 as of $1^{\text {st }}$ June 2020. 
Recently, violent attacks against the health workers are on the rise and they are being attacked and threatened by the relatives of the patients succumbing to complications. This situation is extremely demoralizing and alarming for the medics who risk their lives to save the patients. Therefore, the Govt. of Pakistan should ensure the security and provision of adequate PPE sto the health workers [8] as they are on the frontline in combating the COVID19 pandemic. Moreover, the services of these health workers should be acknowledged instead of blaming them or creating false propaganda against them. There is a need to join hands with these medics and paramedics and fight together like a brave and sensible nation to eradicate the COVID-19 pandemic from Pakistan.

Keywords: COVID-19, Health workers, Pakistan, Pandemic, SARS-CoV-2

\section{Authors' Contribution}

All the authors have contributed equally to this study.

\section{ACKNOWLEDGMENTS}

The authors are thankful to the Vice-chancellor of the University of Okara, Okara, Pakistan for providing support for the accomplishment of this study.

\section{REFERENCES}

1. Singhal T: A review of coronavirus disease-2019 (COVID-19). The Indian Journal of Pediatrics. 2020:87;281-286
2. Bassetti M, Vena A, Giacobbe DR: The novel Chinese coronavirus (2019-nCoV) infections: Challenges for fighting the storm. European journal of clinical investigation. 2020: 50(3):e13209. https://doi.org/10.1111/eci.13209

3. https://www.who.int/emergencies/diseases/novelcoronavirus-2019

4. Waris A, Khan AU, Ali M, Ali A, Baset A: COVID19 outbreak: current scenario of Pakistan. New Microbes and New Infections. 2020:35;100681. https://doi.org/10.1016/j.nmni.2020.100681

5. http://covid.gov.pk/

6. Ng K, Poon BH, Kiat Puar TH, Shan Quah JL, Loh WJ, Wong YJ, Tan TY, Raghuram J: COVID-19 and the risk to health care workers: a case report. Annals of internal medicine. 2020: 172(11):766767.

doi: 10.7326/L20-0175.

7. Adams JG, Walls RM: Supporting the health care workforce during the COVID-19 global epidemic. Jama 2020, 323(15):1439-1440.

8. Lancet $\mathrm{T}$ : COVID-19: protecting health-care workers. Lancet (London, England). 2020; 395(10228):922. 